\title{
COBIJA Y SUS VÍAS DE CONEXIÓN CON EL INTERIOR DE ATACAMA. DESDE LA COLONIA HASTA LA GUERRA DEL SALITRE*
}

\author{
COBIJA AND IT'S CONECTIONS WITH ATACAMA'S HINTERLAND. \\ FROM COLONIAL TIMES TO THE NITRATES WAR
}

César Borie ${ }^{* *}$, Victoria Castro ${ }^{* * *}$, Varinia Varela $^{* * * *}$ y Carlos Aldunate $^{* * * *}$

\begin{abstract}
Contrastando con la imagen de desolación y hostilidad implantada sobre la Depresión Intermedia de Atacama mediante el concepto de despoblado, la transecta altitudinal que une Cobija y Calama se destaca a la luz de la investigación histórica y arqueológica como un escenario en donde distintos grupos humanos desplegaron a lo largo del tiempo diversas estrategias de habitar y transitar, comunicando la costa arreica, la cuenca del Loa medio y los oasis interiores de la Región de Antofagasta.

Integrando estrategias de relevamiento de datos y metodologías de análisis, que incluyen el estudio de cartografía histórica y crónicas, prospecciones arqueológicas y el uso de tecnologías de información geográfica, se abordan los paisajes viales configurados por el desplazamiento de personas y bienes en este espacio internodal en momentos históricos, relevando información respecto de su materialización en rutas de tránsito concretas y a los factores socioeconómicos, geopolíticos, ambientales y tecnológicos que marcaron su surgimiento, uso, reestructuración y abandono.
\end{abstract}

Palabras claves: Cobija, caminos históricos, paisajes culturales, SIG.

Contrating the image of desolation and hostility implanted on the Atacama's Intermediate Depression through the concept of wilderness, the altitudinal transect linking Calama and Cobija stands in the light of historical and archaeological research as a scenario in which different human groups deployed over time various strategies of dwelling and travelling, communicating the coastal desert, the Middle Loa basin and the inner oasis of the Antofagasta Region.

Integrating strategies for data gathering and analysis methodologies, including the study of historical chronicles and maps, archaeological surveys and the use of geographic information technologies, highway landscapes shaped by the movement of people and goods through this internodal space in historical times are addressed, relieving information regarding their realization in concrete transit routes and the socioeconomic, environmental and technological factors that marked their emergence, use, restructuring and neglect.

Key words: Cobija, historical roads, cultural landscapes, GIS.

\section{Introducción: \\ el puerto de Cobija, paisajes y rutas}

En el siglo XIX las nuevas fronteras republicanas, que establecían el límite occidental entre Perú y Bolivia en la desembocadura del río Loa, impulsaron a la República de Bolivia a buscar una conexión marítima por Atacama. La atención de las autoridades bolivianas se volcará con fuerza desde 1827 al antiguo puerto de Atacama La Baja, designando comisionados, destinando recursos y desarrollando políticas de fomento para Cobija.
Este emprendimiento incluyó el mejoramiento de su ruta de acceso desde los nodos altiplánicos, una vía que en tiempos coloniales había sustentado solo un irregular tráfico de mercaderías y minerales que evadían el control administrativo establecido por la Corona española en sus puertos principales (Cajías 1975; Lofstrom 1974; Sanhueza 1991).

La historia de la presencia boliviana en la costa arreica de la Región de Antofagasta estuvo marcada por una dinámica de avances y retrocesos. Los esfuerzos por habilitar y mantener un eficiente sistema de postas para el correo de ultramar y el tráfico

\footnotetext{
* Resultado de los proyectos FONDECYT 1050991 y 1100951.

** Universidad Católica del Norte, Programa de Doctorado en Antroplogía UCN-UTA, San Pedro de Atacama, Chile. Correo electrónico: cesarborie@gmail.com

*** Museo de Arte Precolombino, Santiago, Chile. Correo electrónico: vvarela@museoprecolombino.cl, caldunate@museoprecolombino.cl

***** Universidad Alberto Hurtado, Santiago, Chile. Correo electrónico: macastrr@ uahurtado.cl
} 
de mercaderías desde y hacia el altiplano sur, se vieron continuamente confrontados a una topografía accidentada, climas extremos, catástrofes naturales y la escasez de recursos básicos. Todo esto, en un contexto marcado por las fluctuantes condiciones políticas, sociales y económicas de los nacientes Estados sudamericanos (Cajías 1975; Lofstrom 1974; Haber 2000), dentro de ellas las tentativas altiplánicas por establecer una fluida conexión portuaria por el Pacífico se verán coartadas por el conflicto armado entre Chile y la Confederación Perú-Boliviana (Castro et al. 2012: 120).

Se presentan a continuación los resultados de una aproximación arqueológica histórica que aborda el estudio de la conformación de paisajes viales en el espacio internodal representado por la transecta Cobija-Calama. Territorio que se plantea idóneo para el estudio a nivel local de los desplazamientos humanos en sus espacios de exclusividad, resaltando la importancia de las vías de circulación específicas como una materialidad accesible desde la arqueología y la historia (Berenguer 1994; Hyslop 1992 [1984]; Pimentel 2003).

Abordar el estudio de la materialidad del pasado en su rol activo y sentido social vuelve pertinente el uso del concepto de Paisajes Culturales (Castro et al. 2004), para focalizar la atención en los lazos trazados entre el registro arqueológico y prácticas concretas realizadas en contextos históricos y culturales específicos (Soja 1989), indagando así en las dinámicas de asentamiento y movilidad humana bajo la influencia de las oportunidades presentadas por el ambiente natural y de sucesivas fuerzas sociales, culturales y económicas (Castro et al. 2004: 464).

Se sostiene que es mediante las experiencias cotidianas y recurrentes en el mundo que las personas adquieren conocimiento y se relacionan en un movimiento constante que repercute sobre el paisaje, convirtiéndolo en un registro duradero de las generaciones pasadas que lo habitaron y transitaron (Ingold 2000: 189-190). Son estas experiencias cotidianas las que encausan la construcción social del paisaje en un proceso continuo y dinámico, dentro del cual es posible discriminar una sucesión de formas de percibir el territorio, de paisajes sobreimpuestos y entretejidos (Castro et al. 2012: 98).

\section{Rutas: derroteros y cronología}

Los antecedentes cartográficos y de crónicas recopilados y analizados proporcionan un panorama general que permite identificar y caracterizar las diferentes vías de tránsito de la transecta CobijaCalama, adentrándose en aspectos relativos a su cronología y a la funcionalidad de sus principales postas.

Estos temas son abordados desde un estudio comparativo de las variantes viales individualizadas, en el que se integran datos procedentes del relevamiento de rutas en terreno y el análisis de sus rasgos materiales asociados, además de seguimientos de estas vías por medio de imágenes satelitales. Se destacan tres ejes viales principales: la ruta vía Gatico y Colupo; la ruta vía Gatico y Colupo Nuevo; y la ruta vía Guasilla. A ellos se suman desvíos que se desprenden de estas arterias para dirigirse al mineral de Caracoles (Figura 1).

\section{La ruta Cobija-Calama vía Gatico y Colupo}

Los datos disponibles acerca de la comunicación vial entre Cobija y Calama en tiempos coloniales son escuetos. Los registros más tempranos datan de la primera mitad del siglo XVII, pero solo precisan la distancia que media entre este puerto y la localidad de Chiu Chiu (28 leguas o $65 \mathrm{~km}$ ) ${ }^{1}$ (Vásquez de Espinoza (1948 [1630]), y aportan las primeras noticias acerca de la posta de Colupo (Probanza de Francisco de Otal (1644), citado en Castro 1997).

Con el cambio de siglo, las referencias acerca de las vías de circulación en uso se volverán más detalladas. Este es el caso de la descripción que entrega José Agustín de Arze de la ruta Cobija-Calama en 1786 y 1787 (Hidalgo 1983), complementada con el mapa de Del Pino Manríquez, donde se indica un camino que discurre por la costa al norte de Cobija hasta llegar a la altura de punta Gatico (Figura 2). Desde allí se interna al este para diluirse en la pampa, sin indicar las postas de Chacance y Guacate, situadas por Arze a $7(35 \mathrm{~km})$ y 10 a 11 (50-55 km) leguas de Calama, respectivamente (Hidalgo 1983: 141).

El trazado representado en el mapa referido se correspondería con la vía Cobija-Calama que discurre por la quebrada de Gatico, formando parte del trayecto de 20 a 22 leguas $(100$ a $110 \mathrm{~km})$ con malos pasos y cuestas que Arze describe entre Chacance y Cobija (Hidalgo 1983: 141).

El viaje se realizaba siguiendo una ruta que, luego de superar la cuesta de Gatico, enfilaba al noreste para cruzar la sierra de Colupo y del Buey Muerto, derrotero identificado como aquel ilustrado 


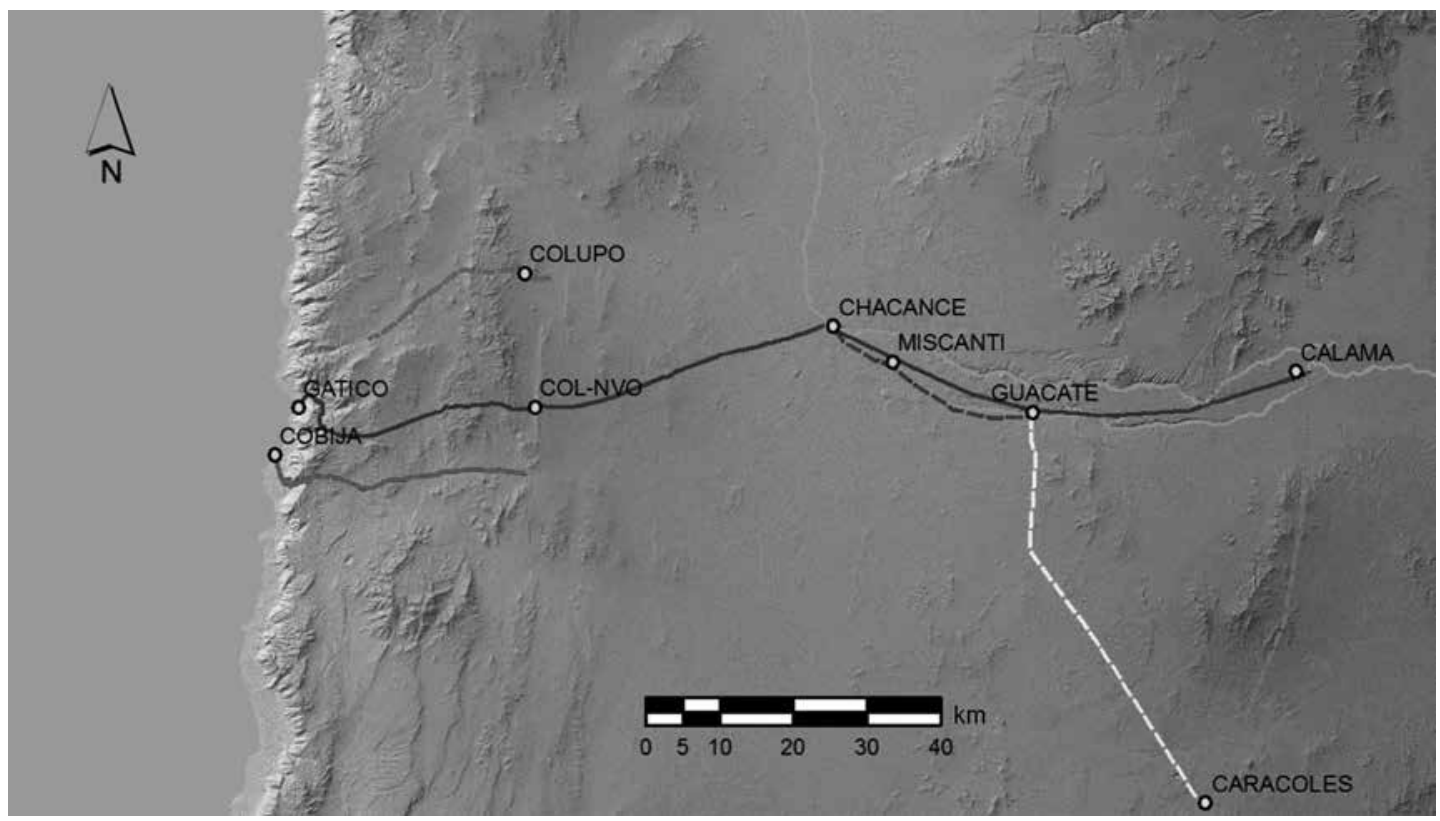

Figura 1. Mapa de las principales rutas, postas y segmentos viales identificados en el área de estudio. Fuente: Elaboración propia.

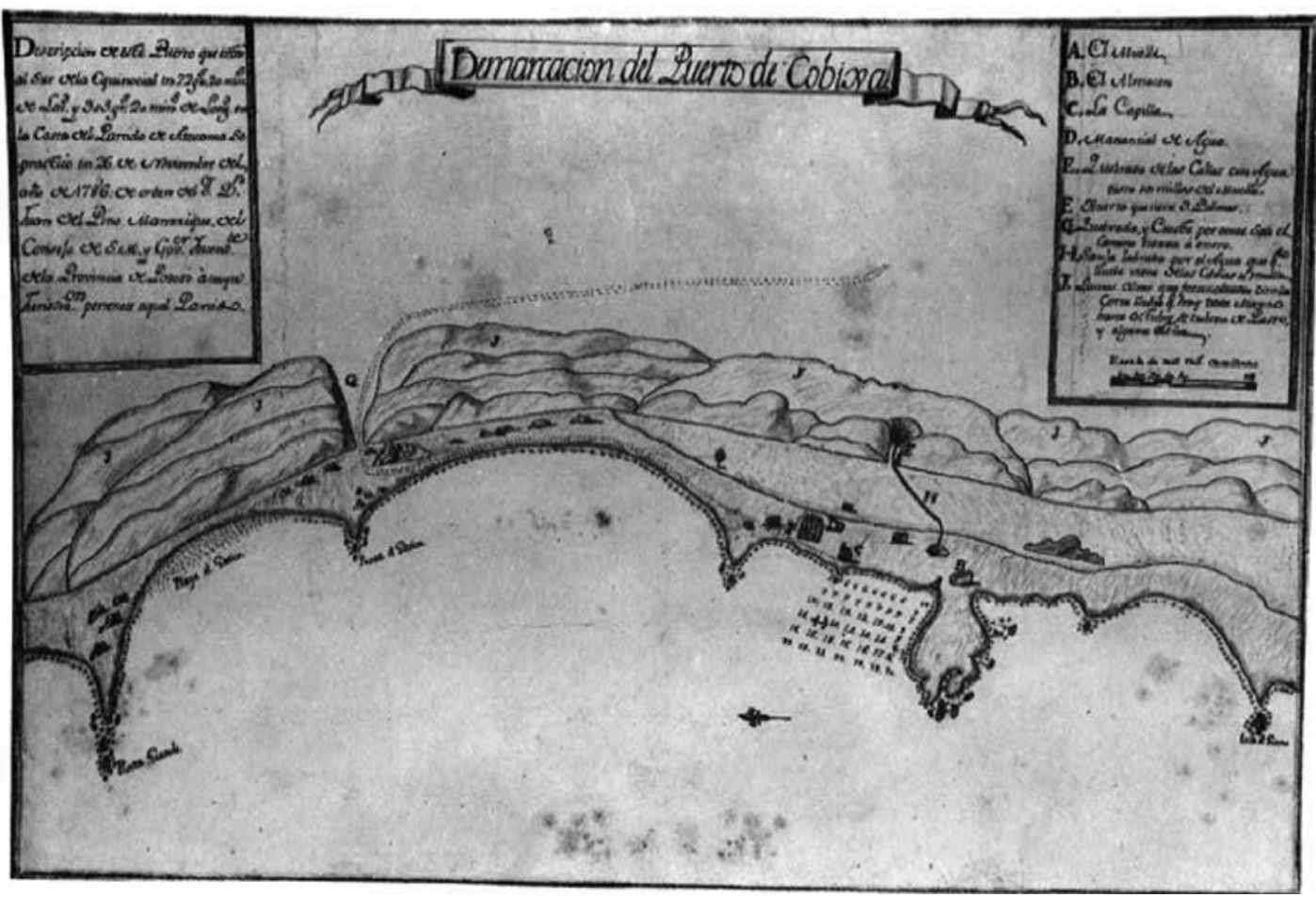

Figura 2. Mapa de Del Pino Manríquez (1786-1787). Fuente: Hidalgo 1983. 
por Pissis en 1875 (2011 [1812-1889]) tocando en la posta de Colupo antes de alcanzar Chacance (Figura 3). Risopatrón a principios del siglo XX representará en su carta la porción occidental de esta ruta (entre Cobija y la sierra de Colupo), pero sin indicar en ella la posta de Colupo (Risopatrón 1910).

Entre Cobija y Chacance, los viajeros solo habrían contado para su reposición con la posta de Colupo (Cajías 1975: 71), punto individualizado previamente por Otal e ilustrado en relación con el "camino a Potosî" en el mapa de 1787 de Cañete y Domínguez (1952 [1787]).

De acuerdo con registros realizados en terreno, la antigua posta de Colupo se encuentra emplazada en los faldeos orientales de la sierra de Colupo y del Buey Muerto, a una altura de $1.645 \mathrm{msm}$ y está conformada por un gran corral rectangular, adyacente a una o dos habitaciones y tres hoyos excavados que conservan en su interior sunchos de barriles, correspondientes a posibles depósitos de agua (Figura 4). Estos rasgos fragmentarios permiten atisbar un panorama coherente con la descripción que entrega Cajías de esta posta a partir de documentación de la primera mitad del siglo XIX, como un punto de reposición mínimamente habilitado con una "media paskana desierta" y sin recursos, donde las inversiones del Estado boliviano para buscar agua no habían dado frutos (Cajías 1975: 79, 90-91).

El derrotero del camino entre Chacance y Calama, común a las tres rutas que se detallan en este apartado, es descrito e ilustrado por Philippi (1860 [1853-1854]) situándolo entre los dos brazos en que se divide el río Loa (San Salvador y Loa o Guacate), lo que resulta coherente con el trazado de la ruta representada en el más antiguo mapa de Arrowsmith de 1844 (Figura 5), con los datos relevados en terreno y mediante el estudio de imágenes satelitales.

Los datos anteriores sugieren que la antigua posta de Colupo se encuentra asociada a una variante

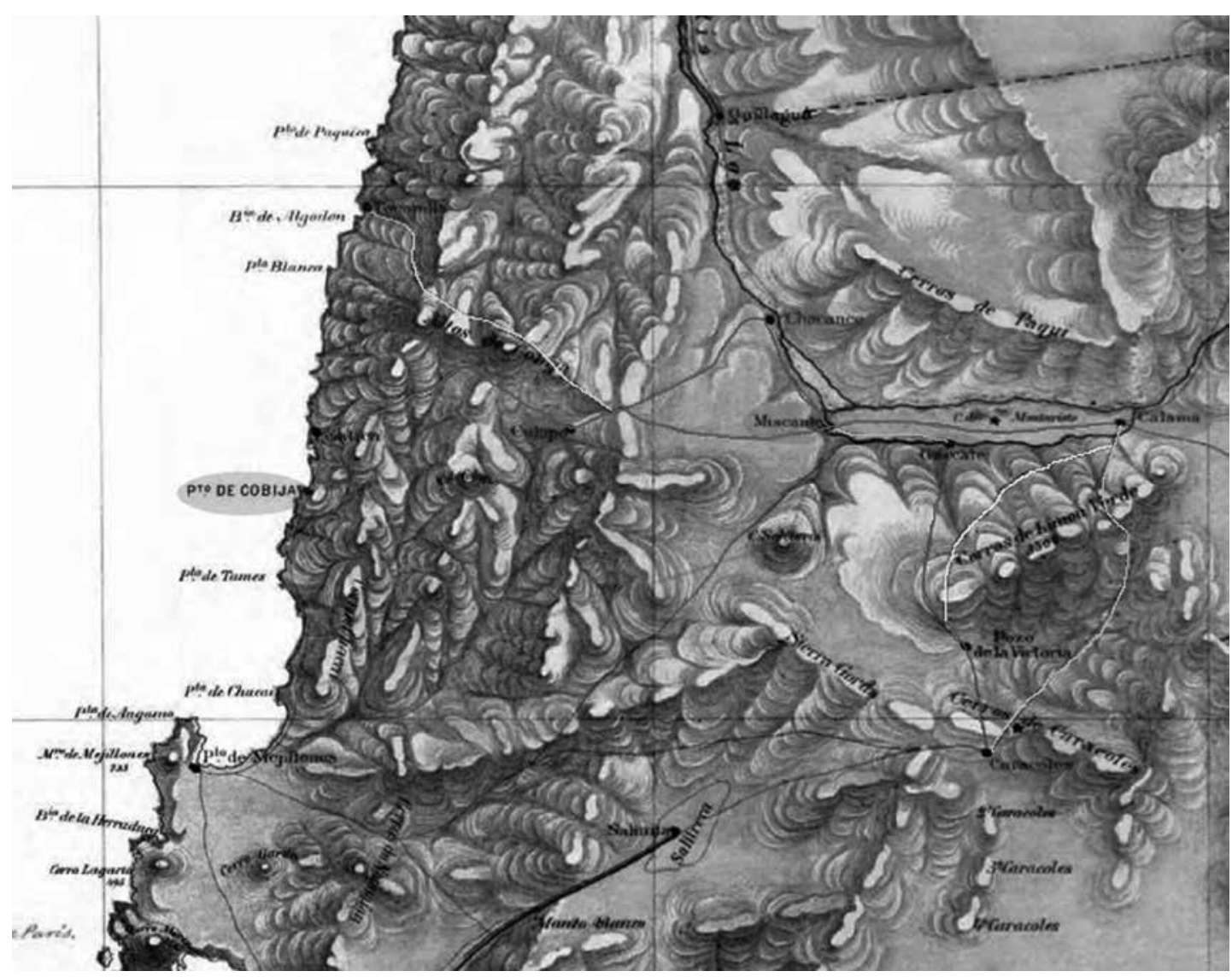

Figura 3. Mapa de Amado Pissis (1875) modificado (Borie 2013, Ms.). Fuente: Pissis (2011 [1812-1889]). 


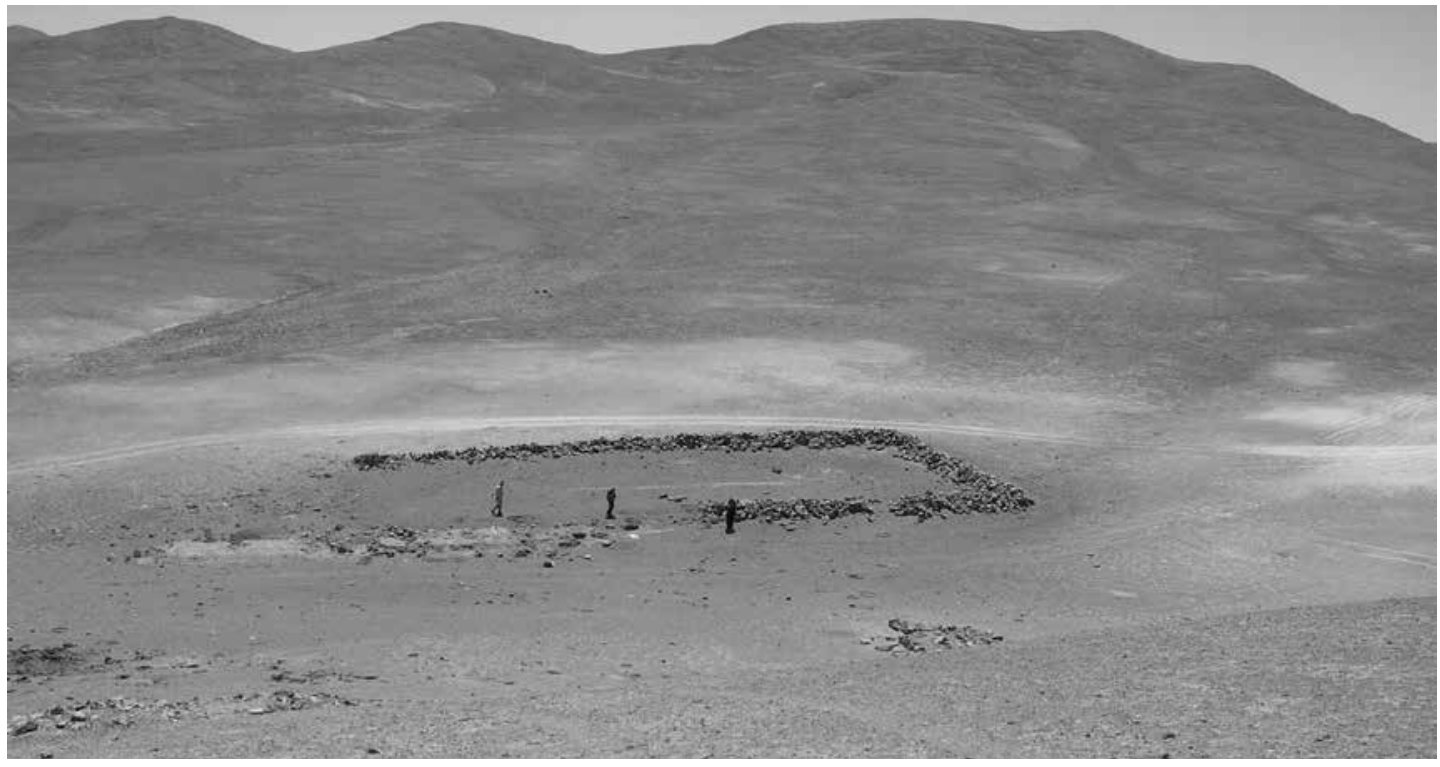

Figura 4. Posta de Colupo. Fuente: Fondecyt 1090551.

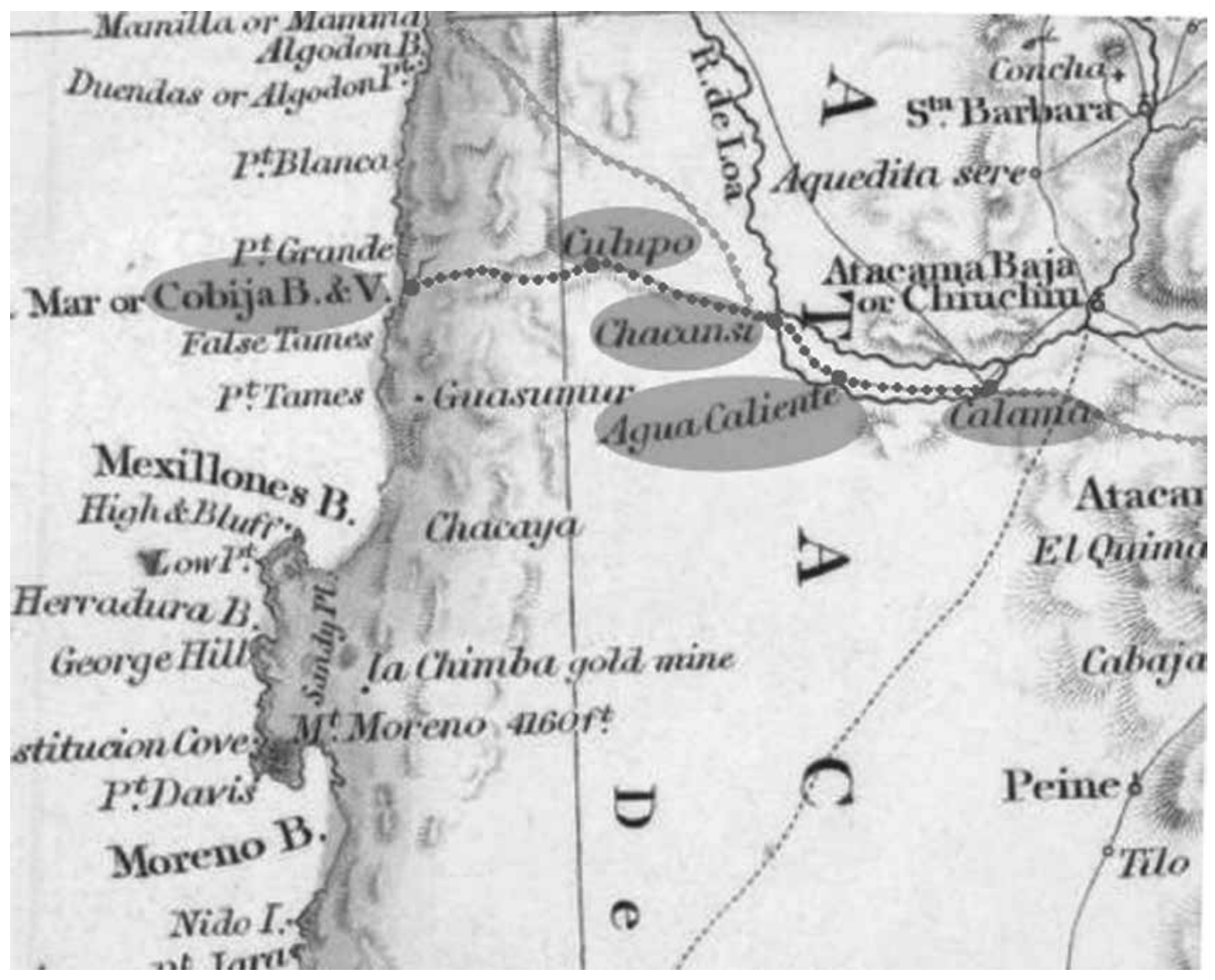

Figura 5: Mapa de Arrowsmith (1844) modificado (Borie 2013, Ms.). Fuente: David Rumsey Map Collection. 
de la ruta Cobija-Calama a través de Gatico, que surca la cordillera de la Costa valiéndose del lecho de la quebrada de Gatico o "cuesta de la Paciencia" (Vidal Gormaz 1879: 9-11). Una vez alcanzada la pampa esta ruta hace un rodeo por el norte para sortear la parte más alta del cordón de Colupo y luego dirigirse a Chacance o conectar con la vía procedente de Tocopilla en Tupiza (Risopatrón 1910).

Esta ruta de data colonial, situación inferida a partir de crónicas, cartografía y reafirmada por el hallazgo en la cuesta de Gatico de cerámica histórica torneada y botijas españolas características del siglo XVIII, continuará en uso en tiempos republicanos, según se puede extraer de las descripciones de D'Orbigny (1958 [1835-1847]), Hernández (1830, citado en Cajías 1975) y Palliere (1858), y de la cartografía proporcionada por Pissis en 1875 (2011 [1812-1889]), manteniendo sus funciones como vía de comunicación al interior, al menos por un tiempo, luego de la Guerra del Salitre (Vidal Gormaz 1879; Risopatrón 1910).

\section{La ruta Cobija-Calama vía Gatico y Colupo Nuevo}

Las primeras referencias directas acerca de esta ruta corresponden a aquellas proporcionadas por el mapa elaborado por Risopatrón en 1910 (Figura 6), las que son complementadas por el diccionario geográfico del mismo autor, donde se especifica que la posta de Colupo Nuevo se localiza a los " $22^{\circ}$ 29' Lat .S. y $70^{\circ} 01^{\prime}$ Lat. W., a $1708 \mathrm{msm}$, al pie suroeste del cerro Colupo, en el camino de Gatico a Chacance" (Risopatrón 1924: 241).

En la carta de Risopatrón (1910) este enclave es posicionado sobre un camino de curso predominante oeste-este entre el puerto de Cobija y Calama, el que corre paralelo al sur de una variante que saliendo de

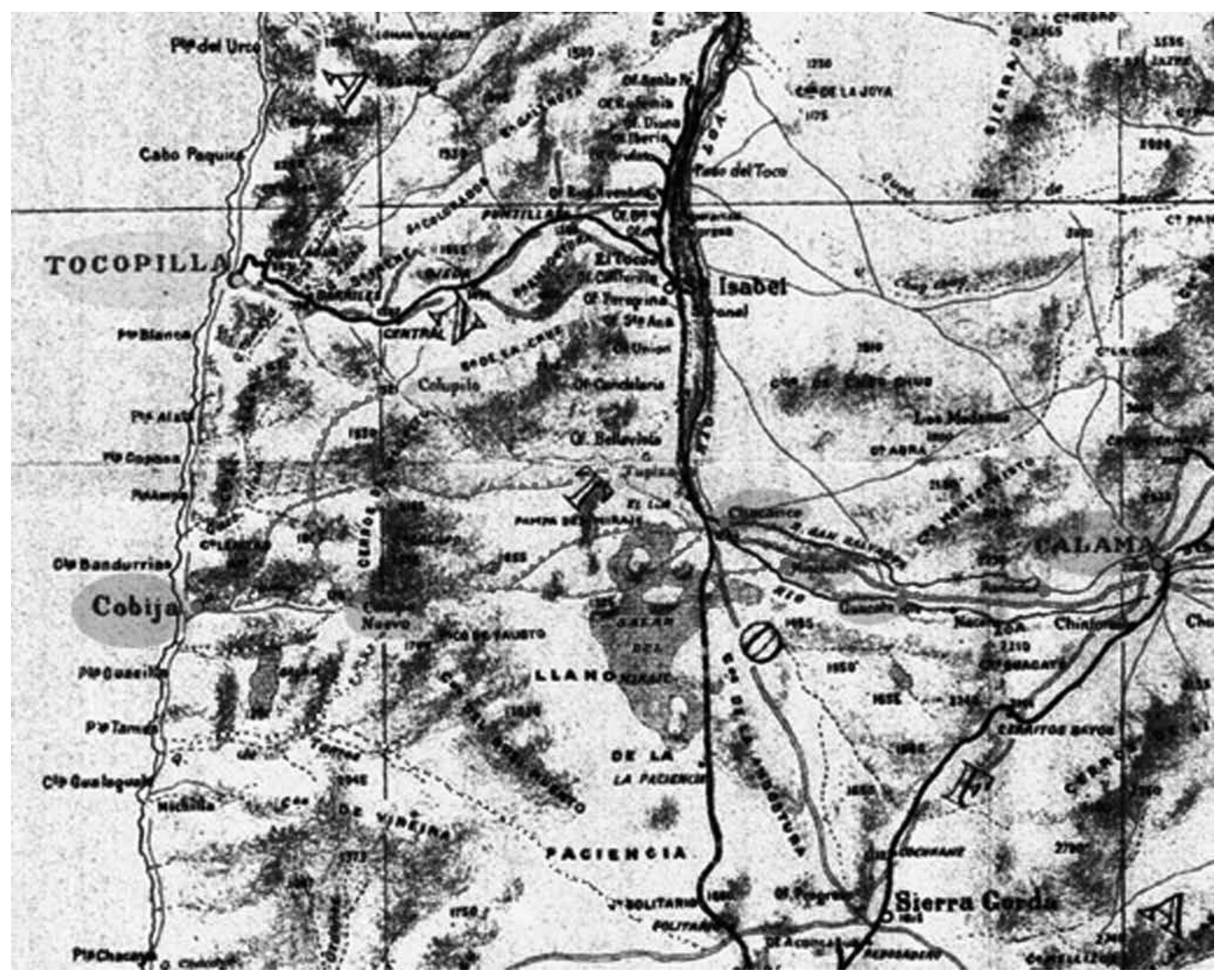

Figura 6. Mapa de Risopatrón (1910) modificado (Borie 2013, Ms.). Fuente: Risopatrón (1910). 
Cobija toma dirección noreste para cruzar la sierra de Colupo y luego intersectar con la vía TocopillaChacance, variante cuya sección occidental fue arriba identificada como la ruta de origen colonial CobijaCalama vía Gatico y Colupo (Figura 6).

Reconocimientos en terreno permitieron localizar la posta de Colupo Nuevo en relación con la arteria que cruza la serranía de Colupo por el "Portezuelo de Colupo", ubicado a $1.790 \mathrm{msm}$, entre el cerro homónimo (por el norte) y el pico de Fausto (por el sur) (Risopatrón 1924: 241), conectando hacia el poniente con Cobija por la quebrada de Gatico y por el oriente con la posta de Chacance, en la confluencia del río Loa y el San Salvador, o directamente con Miscanti.

La posta de Colupo Nuevo se emplaza al oriente de la sierra de Colupo, a una altura de $1.750 \mathrm{msm}$. El sitio se conforma por dos corrales pareados de grandes dimensiones y una estructura pequeña de planta rectangular, posiblemente de carácter habitacional, asociados a importantes acumulaciones de basuras históricas (Figura 7).
Pese a que las características arquitectónicas de este sitio son muy similares a las reseñadas anteriormente para la posta de Colupo, en vista de la ausencia en superficie de materiales de data colonial, la coherencia de las fechas entregadas por las piezas diagnósticas registradas y la información aportada por la revisión de crónicas y cartografía histórica, se plantea que este enclave formaría parte de una ruta trazada alrededor de mediados del siglo XIX entre Gatico y Chacance, irguiéndose como una variante del camino colonial arriba detallado, con el que comparte el tramo costero entre Cobija y la cuesta de Gatico.

En la posta de Colupo Nuevo confluyen otras vías, específicamente un enlace que se desprende de la ruta Tames-Caracoles, descrito por Vidal Gormaz (1879) e ilustrado por Risopatrón (1910), y un camino, sin referencia previa, que se interna por la cordillera de la Costa al sur de Cobija, entre este puerto y punta Tames (Risopatrón 1910). Esta última vía se presume correspondería, al menos en su segmento poniente, a la ruta que se detalla a continuación.

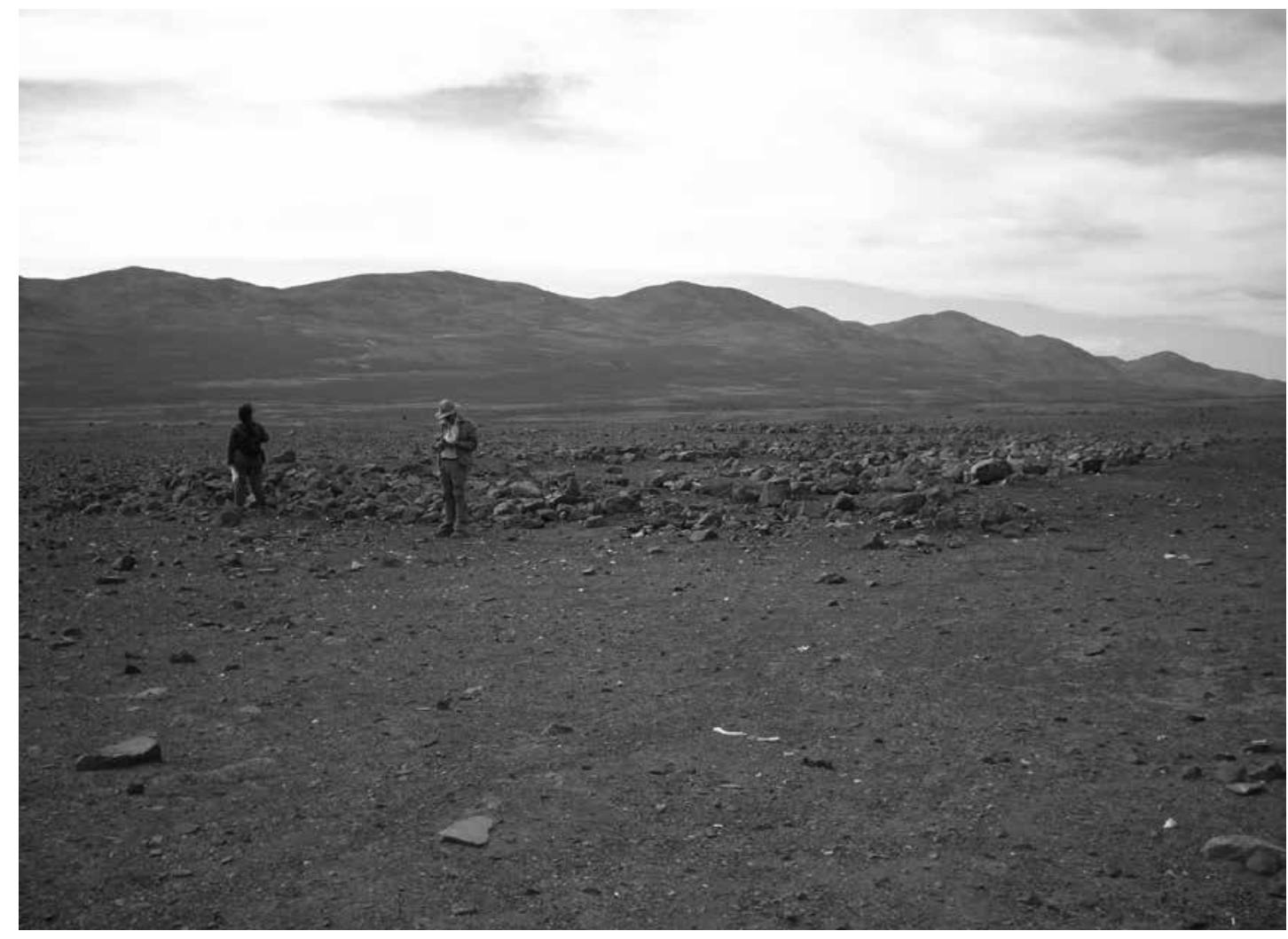

Figura 7. Posta de Colupo Nuevo. Fuente: Fondecyt 1090551. 


\section{La ruta Cobija-Calama vía Guasilla}

Para facilitar el tráfico entre Cobija y Caracoles el gobierno boliviano aprueba en mayo de 1870 la propuesta para abrir una carretera entre Cobija y Calama, esta es puesta en servicio unos meses después (Arce 2004 [1930]: 103; Cajías 1975: 92). El surgimiento de esta arteria, identificada como la ruta Cobija-Calama vía Guasilla, se encuentra íntimamente ligado al explosivo crecimiento del mineral de plata de Caracoles, yacimiento que se convertirá rápidamente en un nodo de confluencia de caminos (Arce 2004 [1930]; Bravo 2008). Un hecho que queda claramente reflejado en el mapa de Bresson de 1871 (1875), pese a que este fue realizado solo un año después de su descubrimiento (Figura 8).
La vía trazada en la quebrada de Guasilla contrasta con las rutas previamente reseñadas en este apartado, en especial en lo que respecta a su porción occidental, ya que las alternativas viales de más antigua data fueron diseñadas aprovechando el cauce de la quebrada de Gatico para comunicar costa y pampa, situación que permite caracterizarlas como rutas de trazado geomórfico, es decir, que adaptan su derrotero a la topografía natural del terreno (Figura 9).

La ruta de Guasilla, en tanto, para sortear los $1.200 \mathrm{msm}$ que alcanza el farellón costero a la altura de punta Guasilla (4 km al sureste de Cobija), requirió de una gran inversión de trabajo en el corte y reforzamiento de las laderas de la abrupta quebrada de Guasilla, integrando soluciones arquitectónicas sofisticadas, fruto de una

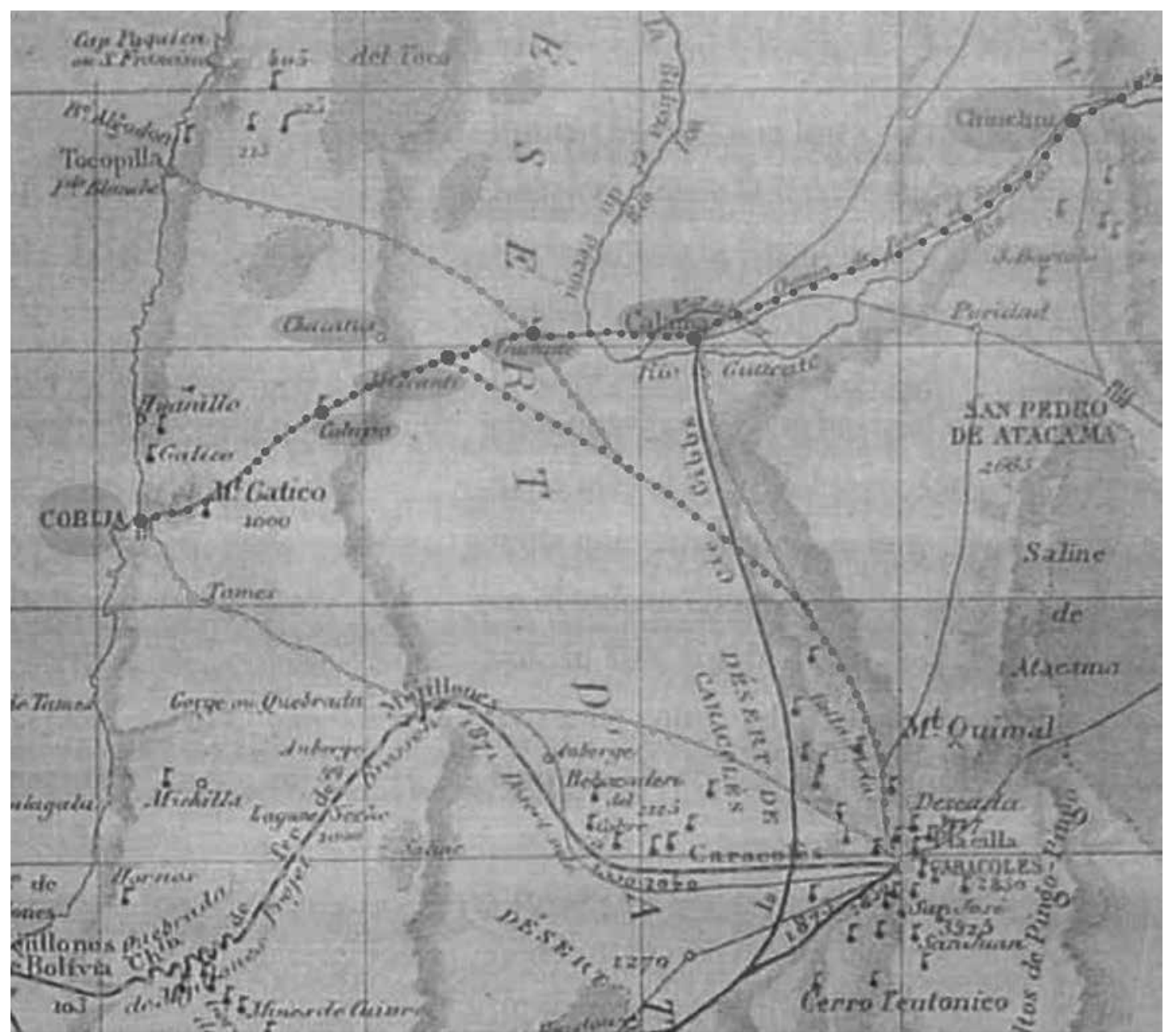

Figura 8. Mapa de André Bresson (1871) modificado (Borie 2013, Ms.). Fuente: Bresson 1875. 


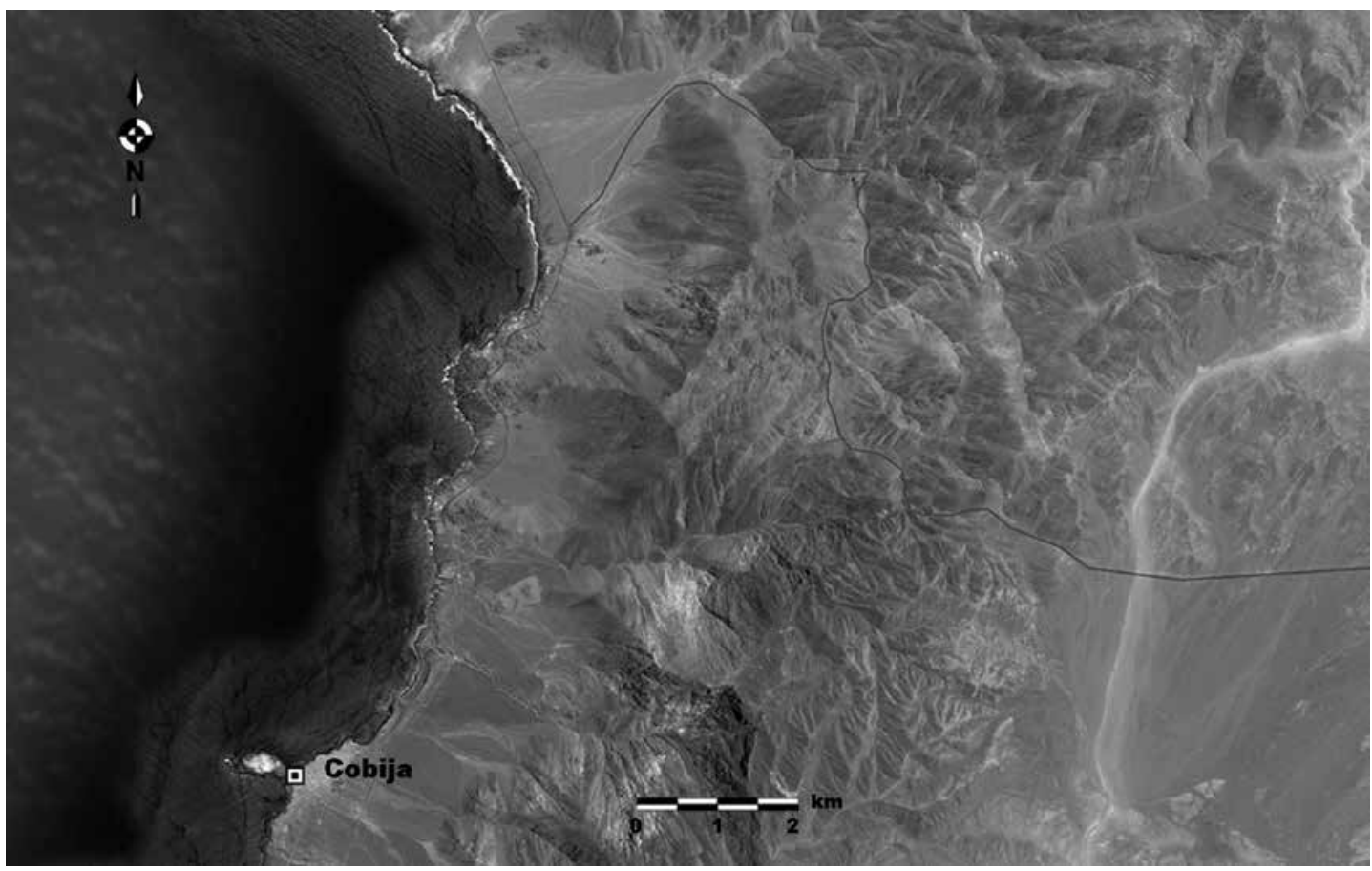

Figura 9. Delineado de la cuesta de Gatico. Fuente: Google Earth.

precisa labor de diseño y recurrentes trabajos de mantención dirigidos a posibilitar un desplazamiento regular de arreos y carretas por apretadas curvas de retorno (Figura 10).

Hacia el interior la ruta Cobija-Calama vía Guasilla adquiere un curso predominante oeste-este para evadir la sierra de Colupo y del Buey Muerto por su extremo sur, cruzando por un portezuelo de $1.450 \mathrm{msm}$, que se ubica entre las estribaciones hacia el sur del cerro de Colupo y el pico de Fausto (Rissopatrón 1910; 1924) (ver Figura 11).

La más moderna y eficiente ruta de Guasilla se mantendrá en funcionamiento, al menos por un par de décadas, luego de que Cobija pase a manos chilenas. Esto si tomamos en cuenta que se trata de la misma ruta descrita en las exploraciones de la Marina de Chile en 1887 (Pomar 1887), su individualización en el mapa de Risopatrón de 1910 y la concentración en la segunda mitad del siglo XIX de los rangos cronológicos aportados por los materiales históricos asociados directamente a esta vía, procedentes tanto de la cuesta de Guasilla como del sitio de descanso, o paradero, denominado Despeñadero, identificado en el punto en que esta cuesta alcanza la pampa.

\section{Paisajes en movimiento}

El panorama general esbozado por esta investigación hace posible comprender las dinámicas de tránsito en la transecta altitudinal en estudio como el resultado de un continuo ajuste entre tradición y cambio, donde los rigores impuestos por las duras condiciones del territorio determinaron una conducta racional y altamente conservadora al momento de definir los derroteros de las vías y seleccionar aquellos espacios más propicios para la reposición de los viajeros y sus animales de carga.

Lo anterior se evidencia en una ocupación redundante de aquellos enclaves específicos que se formalizaron como postas. Estos nodos siguieron funcionando, independientemente de las comodidades que ofrecían sus instalaciones, como piezas clave de un movimiento reorientado continuamente de acuerdo con la emergencia o decadencia de polos productivos, y a la masificación de las nuevas tecnologías para el transporte.

Pese a este importante rasgo de continuidad, que sitúa a las postas que jalonan las rutas entre Cobija y Calama como una materialidad que trasciende la secuencia histórica estudiada, es posible discriminar 


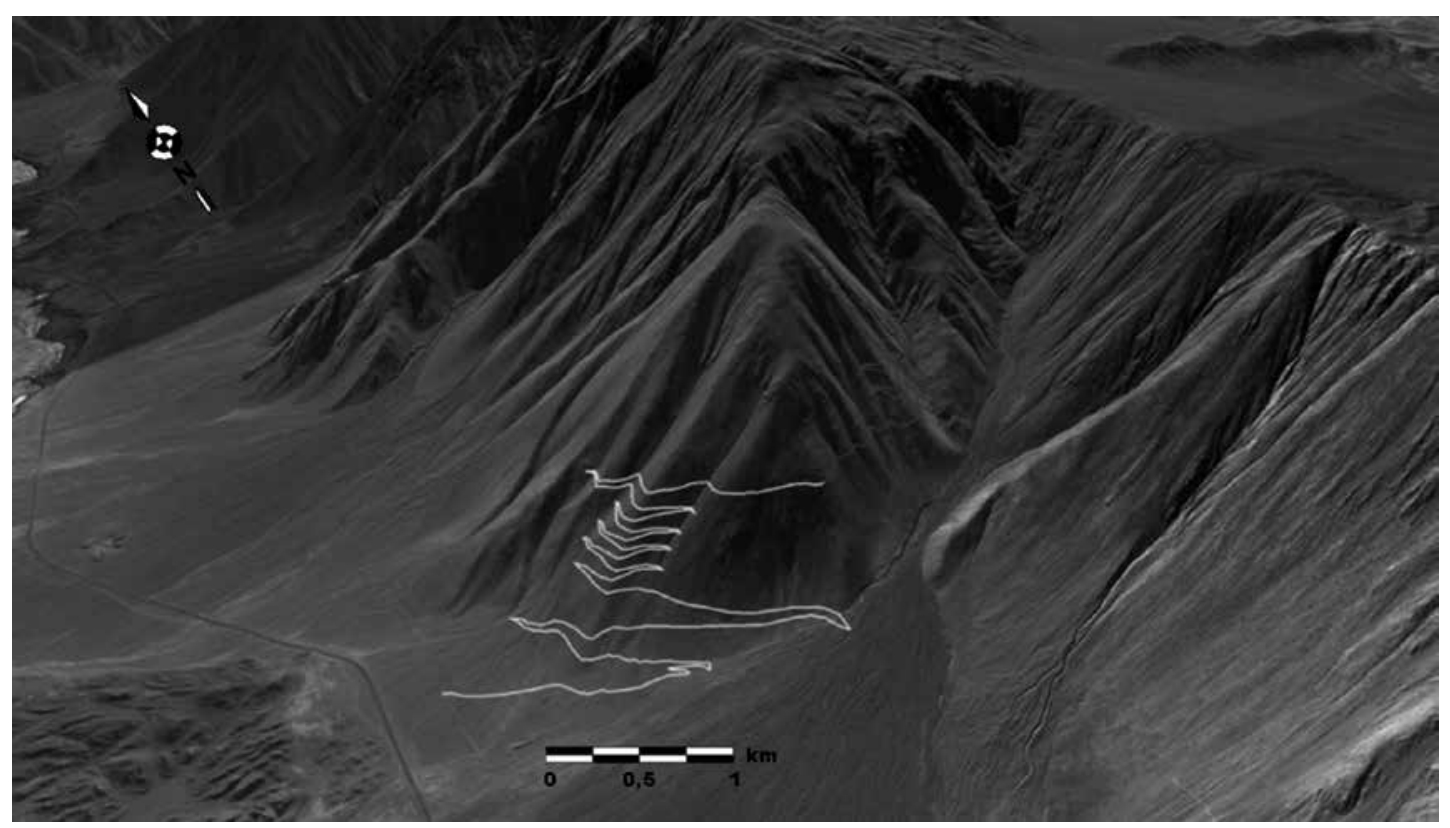

Figura 10. Delineado de la cuesta de Guasilla. Fuente: Google Earth.

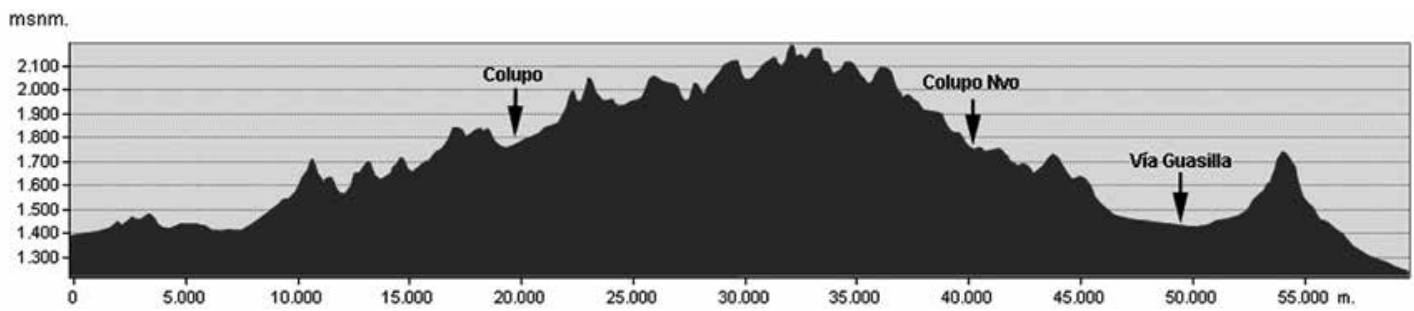

Figura 11. Perfil altitudinal de la sierra de Colupo y del Buey Muerto indicando su relación con las rutas y postas en estudio. Fuente: Elaboración propia.

dos escenarios principales, cuyas características particulares se sintetizan a continuación con el propósito de esbozar paisajes viales diferenciados, uno colonial y otro republicano.

\section{El paisaje vial colonial}

Este paisaje es aquel que se configura en la región atacameña a partir de su integración al dominio español y a un esquema organizativo dentro del cual la costa de Cobija quedó comprendida en la parcialidad de Atacama La Baja (Cajías 1975; Sanhueza 1991).

La presencia de una población pescadora en la ensenada de Cobija y su antigua relación con el interior de Atacama (Lozano Machuca 1885
[1581]: 145), sumada a la riqueza de sus costas y al riesgo que implicaban las ocasionales visitas de piratas y contrabandistas, vulnerando los circuitos comerciales instaurados por los hispanos, atraerán tempranamente el interés de la Corona (Aldunate et al. 2010; Cajías 1975), la que desplegará varias estrategias coercitivas para encauzar su producción pesquera a los mercados de los centros urbanos y mineros del altiplano, valiéndose para ello de la vasta experiencia de los grupos atacameños en este tipo de trajines.

El transporte de pescado era realizado a cuestas desde Cobija hasta Chiu Chiu, punto desde donde su traslado a las provincias altiplánicas era facilitado gracias al empleo de recuas de llamas (Sanhueza 1991: 51). El alto costo que significaba el transitar 
por los parajes de extrema aridez que comunicaban con el litoral atacameño, habría coartado el uso de rebaños de camélidos en el eje Cobija-Calama/Chiu Chiu, salvo en los "tiempos de lomas" cuando, producto de lluvias excepcionales, brotaban pastos en los cerros del litoral desértico (Sanhueza 1991: 174-175).

Este escenario cambiará en el siglo XVII con la introducción de ganado mular, emprendimiento impulsado por la Iglesia y controlado mediante los sistemas de servicio personal y de reparto por los corregidores (Hidalgo 1982: 196; Sanhueza 1991: 71). La mayor rapidez, resistencia y capacidad de carga de estos animales (Nielsen 2001) agilizará el tráfico en este trayecto occidental de la ruta Cobija-Potosí, abriendo nuevas posibilidades de tránsito y gatillando cambios a nivel económico, social y tecnológico en la sociedad indígena local (Sanhueza 1991: 79, 84-86).

Hacia fines del régimen colonial, varios factores concurrirán para producir el decaimiento comercial del Virreinato del Perú. A la explotación por parte de los corregidores de la mano de obra indígena y las pesadas cargas tributarias por ellos impuestas (Hidalgo 1982: 195-202), se sumará la inestabilidad política derivada del rápido recambio de las autoridades hispanas locales y de alzamientos indígenas (Sanhueza 1991: 143-144). A su vez, la creación en 1776 del virreinato de La Plata redirigirá al Atlántico, específicamente a Montevideo y Buenos Aires, el tráfico mercantil que se realizaba desde inicios de la Colonia por los puertos del Pacífico (Cajías 1975: 18; Lofstrom 1974: 186).

La disminución del flujo comercial en los puertos de Lima, Arica y Cobija configurará un nuevo esquema que debió afectar significativamente los circuitos de tráfico comercial, perjudicando entre otros a los arrieros atacameños (Hidalgo 1982: 205) e incidiendo en el estado de abandono en que las crónicas coinciden al describir al puerto de Cobija hacia fines del siglo XVIII (Cañete y Domínguez 1952 [1787]; del Pino Manríquez 1787, citado en Hidalgo 1983). Esto pese a que para ese momento se reporta un mayor movimiento de mercaderías y plata por este puerto, producto del arribo de barcos procedentes de Perú y Chile (Casassas 1974).

Durante todo el período colonial Cobija mantendrá un rol secundario respecto de puertos mejor habilitados y con conexiones más directas hacia el altiplano sur, como fue el caso del Callao y, a partir de 1570, de Arica (Cajías 1975: 16). Es por ello que se configura un paisaje vial colonial de carácter marginal, donde el irregular tráfico entre Cobija y Calama era encauzado por medio de un único eje, trazado en la cuesta de Gatico y pasando en su avance hacia el interior por las postas de Colupo, Chacance y Guacate.

Esta vía corresponde a la materialización de una estrategia de conexión informal, que se vale de corredores naturales, como la quebrada de Gatico, para diseñar su derrotero y alcanzar la posta de Chacance, punto donde la ruta se interna hacia Calama.

La distancia entre los sitios de enlace de esta arteria no supera los $48 \mathrm{~km}$ (tramo Cobija-Colupo) promediando $39,6 \mathrm{~km}$. Cifra que se encuentra en el límite inferior del rango de alcance estimado por jornada de viaje ${ }^{2}$ y se considera adecuada en función de las características del derrotero, con extensos arenales, cuestas y baja o nula inversión arquitectónica, y las condiciones originales de funcionamiento de la ruta, que hasta el siglo XVII habría sustentado un tráfico pedestre, sumándose solo con posterioridad a esta fecha el de arreos y carretas.

\section{El paisaje vial republicano}

Las fronteras de las nuevas repúblicas sudamericanas formadas a principios del siglo XIX reprodujeron en gran medida aquellos límites fijados en la Colonia entre el Alto y el Bajo Perú para dividir los territorios de las naciones de Perú y Bolivia. Arica, el puerto natural de La Paz en virtud de su proximidad y facilidades de acceso desde este enclave boliviano, quedaba ahora bajo jurisdicción peruana (Lofstrom 1974: 186). Surge así la costa de Atacama y la ruta trazada desde allí hacia Potosí como una vía que ofrecía la anhelada independencia comercial a Bolivia (Lofstrom 1974: 189).

En consecuencia, en 1825 Simón Bolívar decreta la fundación del Puerto de Lamar, elevando la categoría de la antigua caleta de Cobija a la de único puerto y centro comercial boliviano en la costa Pacífico, acto al que suceden leyes dirigidas a favorecer la introducción de mercaderías por este puerto y el establecimiento de una mayor población en la localidad (Lofstrom 1974: 197-198, Cajías 1975: 72).

Las tentativas del gobierno boliviano para habilitar el camino que unía Cobija y Potosí se iniciarán formalmente en 1827, durante el gobierno 
de Sucre, chocando reiteradamente con las duras condiciones del trayecto, las que se podrían resumir en la falta de agua y forraje para el consumo de los animales, la dificultad para conseguir postillones y la carencia de postas con los recursos básicos para reponer a viajeros y arreos (Cajías 1975: 69-70, 87).

No obstante se destinaron los fondos de la Aduana para el arreglo de todas las postas del camino de Cobija, estas facilidades continuaban despobladas a inicios de la década de 1840, hecho que se atribuye a la escasez de población y su dedicación mayoritaria a la arriería, en momentos en que Cobija experimentaba el esplendor económico gatillado por el inicio de la explotación del guano y de la inclusión de este puerto como escala obligada dentro del itinerario de vapores entre Valparaíso y El Callao (Arce 2004 [1930]: 21; Cajías 1975: 92).

La dificultad del gobierno boliviano para mantener el sistema de postas entre Cobija y Potosí, encuentra su correlato en las diversas $-\mathrm{y}$ muchas veces alternadas- condiciones de funcionamiento y abandono de las postas descritas por funcionarios y viajeros a lo largo de la década de 1830 , situación que no había podido ser revertida en la década siguiente, cuando la mayoría de las postas se reportan en estado de abandono y descuidadas (Cajías 1975: 91). Seguirán, sin embargo, figurando en el trayecto entre Cobija y Calama las mismas escalas (Colupo, Chacance y Guacate) en las crónicas de viaje de exploradores entre las décadas de 1850 y 1870 (Larraín 1979), denotando su sostenido uso en el tiempo. Se sumará a ellas luego la posta de Miscanti, vinculada a la explotación minera en Tocopilla y a la ruta de conexión trazada desde este puerto al interior, hacia Chacance y Calama, o al floreciente mineral de Caracoles.

La minería en Atacama adquirirá en la segunda mitad del siglo XIX un importante impulso gracias al auge de la explotación del cobre (Aldunate $e t$ al. 2008: 111). Los caminos carreteros que conectaban los minerales y las faenas salitreras con Cobija, surcados desde 1874 por las más grandes y resistentes carretas de huella (Arce 2004 [1930]: 280), serán intensamente utilizados en estos momentos. Su arreglo y mantención estará a cargo de cuadrillas de trabajadores destinados exclusivamente a este propósito (Arce 2004 [1930]: 282).

La proyección de la redes ferroviarias en la región a inicios de la década de 1870 (Thomson 2006: 141) no acabará de manera drástica con este tráfico de arreos y carretas, pero sí reducirá y reorientará su flujo a rutas subsidiarias a las paradas del ferrocarril y al interior de las faenas calicheras (Conti 2006: 100).

El puerto de Cobija, tomado en armas por Perú en 1835 y 1853 , y objeto del bloqueo comercial español de 1866-1867, será embestido por terremotos, maremotos y epidemias de fiebre amarilla entre 1868 y 1877 (Arce 2004 [1930]). Cobija se levantará, pero el contrato de transporte animal para la ruta comercial entre este puerto y Potosí continuará decreciendo hasta la toma de posesión de Atacama por parte del gobierno chileno.

Con la ocupación chilena, y especialmente después de la extensión del ferrocarril de Antofagasta hasta la frontera con Bolivia entre 1884-1892, la mayoría de los arrieros atacameños se verán forzados a volcarse al creciente mercado de la sal, comercializada entre los refinadores de plata de la vertiente oriental de los Andes (Platt 1995: 279), giro que coincide con el cierre del primer y más esplendoroso ciclo del mineral de Caracoles en 1890 (Bravo 2008).

Cobija quedará a la sombra de los puertos salitreros de Pisagua, Iquique, Tocopilla, Mejillones, Antofagasta y Taltal, cayendo en desuso sus rutas de comunicación al interior, las que serán parcialmente reutilizadas por pirquineros y para el tránsito de los vehículos motorizados introducidos en la región a partir de la década de 1910 (González 2008).

El paisaje vial republicano estructurado en estas circunstancias se diferencia de aquel esbozado para tiempos coloniales, ya que se relaciona con los influjos económicos y conflictos políticos y territoriales de los nuevos Estados nacionales sudamericanos.

En este complejo escenario, el diseño, construcción, uso y mantención de las rutas -y sus postas- se encontraba mediado por el gobierno boliviano. La ruta Cobija-Calama vía Colupo Nuevo emerge en este contexto como una variante de la antigua arteria colonial trazada a través de la más nortina posta de Colupo. La puesta en servicio de la ruta vía Colupo Nuevo habría abierto la posibilidad de nuevos itinerarios en el trayecto Cobija-Calama, permitiendo, en condiciones óptimas, la conexión de estos nodos en tres jornadas, haciendo escalas solo en Colupo Nuevo y Miscanti. Esto implica un avance promedio por jornada de $50,9 \mathrm{~km}$, cifra que, si bien se encuentra relativamente más próxima al tope del rango planteado a partir de las mediciones y modelamientos realizados, se estima factible, debido a las mejores condiciones para el desplazamiento 
que habría generado la inversión estatal y privada sobre las vías, la mayor disponibilidad de animales de carga, de forraje introducido para sustentarlos y la incorporación de las más eficientes carretas de huella.

No obstante la ruta Cobija-Calama vía Colupo Nuevo constituye un buen ejemplo del nuevo escenario vial republicano, la posterior ruta abierta por la cuesta de Guasilla se plantea como un caso paradigmático, en tanto evidencia una gran inversión de mano de obra para su construcción y mantención, y refleja el perfeccionamiento de una lógica vial optimizadora que se rige por estándares de diseño sólidos, manifiestos en la coherencia de los parámetros constructivos de los distintos segmentos y subsegmentos que conforman el complejo tramo de camino carretero empleado para superar la quebrada de Guasilla y conectar de manera más rápida y directa el puerto de Cobija con el interior de Atacama, estableciendo un nexo estrecho con el mineral de Caracoles.

\section{A modo de conclusión: cerrando la jornada}

Para cerrar este escrito es preciso aclarar que la distinción arriba presentada no se plantea como una dicotomía rígida, sino que se reconoce el entrecruzamiento de distintos paisajes producto de su inmersión en la temporalidad y espacialidad del tránsito arriero. La arriería, como ha sido planteado por otros investigadores y se pudo apreciar en las páginas anteriores, constituyó un mecanismo efectivo de inserción de la población indígena de Atacama dentro de la nueva estructura económica colonial, favoreciendo la reproducción de patrones y dinámicas interregionales de larga data, los que se integraron dentro de los nuevos circuitos comerciales trazados en torno a los centros mineros (Martínez 1985; Sanhueza 1991), énfasis minero que seguirá actuando como un eje estructurador de la arriería en tiempos republicanos, formando parte fundamental del proceso de consolidación de los nuevos Estados sudamericanos y de la expansión de sus territorios nacionales hacia zonas marginales y poco ocupadas (Haber 2000: 20).

Los arrieros atacameños serán los principales responsables de la producción del paisaje vial pampino, dando, mediante sus acciones y relaciones sociales cotidianas, forma concreta a una espacialidad que se materializa en rutas y postas.
Se plantea por ello la pertinencia del concepto de paisaje de tarea o taskscape, en tanto funde en el espacio una temporalidad actuada por -y encarnada en- los arrieros en sus movimientos (Ingold 2000), temporalidad que se liga de manera concreta e indisoluble a las actividades desplegadas por ellos para asegurar el tránsito en la transecta Cobija-Calama, un paisaje cuyas restrictivas condiciones ambientales habrían repercutido en el uso recurrente de viejas rutas naturales, como la cuesta de Gatico, y en el aprovechamiento sostenido de aquellos enclaves que desde inicios del período colonial fueron habilitados como postas.

Lo anterior indicaría la persistencia de lógicas de movilidad que se proyectan en el tiempo como estrategias viables gracias a la habilidad de los arrieros para articular de manera efectiva un conocimiento íntimo de las capacidades y limitaciones de sus animales de carga, los vaivenes del sistema mercantil en desarrollo y las oportunidades ofrecidas por la geografía local. Elocuentes en este sentido son los regulares parámetros de pendiente registrados en las distintas alternativas viales estudiadas $^{3}$ y la consistencia, en términos generales, de las distancias y tiempos por jornada de viaje de los distintos itinerarios empleados para comunicar Cobija y Calama.

Es importante destacar en este punto las diversas -y muchas veces alternadas- condiciones de funcionamiento en que se retratan las postas de Colupo, Chacance, Miscanti y Guacate en tiempos republicanos (Cajías 1975; Larraín 1979), dinámica de habilitación y abandono que no da cuenta de una correlación entre momentos de auge de Cobija y mejores condiciones en las rutas y sus escalas. Esta situación puede ser entendida como el choque de políticas instauradas desde un gobierno central, que buscaba homogenizar los servicios disponibles en las postas para auxiliar a viajeros, autoridades y comerciantes de la ruta Cobija-Potosí, con un escenario donde la falta de recursos básicos, como agua, forraje y mano de obra, dificultaban la habilitación de estructuras duraderas y la presencia estable de maestros de postas, pese a los incentivos ofrecidos a estos.

La alta movilidad, profundamente arraigada en los arrieros atacameños, resultaba inconciliable con su presencia fija en un espacio artificialmente diseñado para satisfacer necesidades impuestas desde afuera de su órbita de acción. Para ellos, tenaces viajeros, la presencia de buenos corrales y un muro o estructura ligera, como los documentados para 
las postas de Colupo y Colupo Nuevo, habrían sido suficientes para su reposición y la de sus animales en un tramo crítico, donde el avance a paso ligero para alcanzar las aguas del Loa y los pastos de las vegas de Calama era prioridad.

A lo largo de estas páginas se ha buscado resaltar, por medio de la integración de viejas y nuevas metodologías, el rol de los arrieros como agentes históricos que a partir de su trajín forjaron extensas redes de interacción en la pampa de Atacama, redes que con el paso del tiempo se materializaron como vías de tránsito formales y fueron vitales para el desarrollo socioeconómico de una zona marcada por la amplia dispersión espacial de sus recursos básicos, enclaves productivos y núcleos poblacionales.

Hacia el interior, las rutas que comunicaban Cobija y Calama se han ido borrando por la acción de lluvias torrenciales y rodados, sirviendo ocasionalmente para el desplazamiento de pirquineros en su incesante búsqueda de nuevas vetas de mineral en la Cordillera de la Costa. En la pampa, las faenas salitreras han disturbado con sus pozos calicheros grandes extensiones de terreno por los que discurrían los trazados viales, persistiendo solo algunos tramos bien conservados y otros obliterados por caminos secundarios, transitados por vehículos motorizados desde principios del siglo XX.

No obstante su estado fragmentado actual, las rutas siguen vivas, acogiendo a nuevos actores y comunicando distintos nodos, participando así de una historia que reorienta constantemente sus derroteros en el andar.

\section{Agradecimientos}

A Edgardo Araneda, Diego Salazar, César Parcero, Pastor Fábrega, Camilo Robles, Manuel Escobar, Christián Sandoval y Catalina Soto.

\section{Referencias Citadas}

Aldunate, C., Castro, V. y Varela, V.

2010 Los atacamas y el pescado de Cobija en homenaje al maestro John Víctor Murra. Chungara 42: 341-347.

Anuario Hidrográfico de la Marina de Chile

1987 Número 12, Año 12, Imprenta Nacional, Santiago.

Arce, I.

2004 [1930] Narraciones Históricas de Antofagasta, PROA, Antofagasta.

Arrowsmith, J.

1844 Map of South America. Escala 1: 12.672.000. Soho Square, Londres.

Berenguer, J.

1994 Asentamientos, caravaneros y tráfico de larga distancia en el Norte de Chile: El caso de Santa Bárbara. En De Costa a Selva: Producción e Intercambio Entre Los Pueblos Agroalfareros de Los Andes Centro Sur, editado por M. E. Albeck, pp. 17-50. Instituto Interdisciplinario Tilcara, Tilcara.

Borie, C.

2013 De la pampa a la costa y de la costa a la pampa. Estudio de un espacio clave de la ruta entre Cobija y Calama. Tesis para optar al título de arqueólogo. Universidad de Chile, Santiago.

Bravo, C.

2008 La plata de Caracoles: un capítulo de la historia chileno-boliviana. En El Mineral de Caracoles. Arqueología e Historia de Un Distrito Minero de La Región de Antofagasta (1870-1989), editado por F. Gracía-Albarido, F. Bravo, F. Rivera y R. Lorca, pp. 19-58. Consejo Nacional de la Cultura y las Artes, Santiago.

Bresson, A.

1875 Le désert d'Atacama et Caracoles (Amérique du Sud) 1870-1874. Le Tout du Monde. Nouveau Journal des Voyages XXXIX, Fasc: 750-751, 321-352.
Cajías, F.

1975 La provincia de Atacama, 1825-1842, Instituto Boliviano de Cultura, La Paz.

Cañete y Domínguez, P. V.

1952 Guía de la Provincia de Potosí. Colección de la Cultura Boliviana, Editorial Potosí, Bolivia.

Casassas, J. M.

1974 La región atacameña en el siglo XVII, Universidad del Norte, Antofagasta.

Castro, V.

1997 Huacca Muchay. Evangelización y Religión Andina en Charcas, Atacama La Baja, Tesis para optar al grado de Magíster en Historia, mención Etnohistoria. Universidad de Chile, Santiago.

Castro, V., Aldunate, C. y Varela, V.

2012 Paisajes Culturales de Cobija, Costa de Antofagasta, Chile. Revista chilena de antropología 26: 97-128.

Castro, V., Varela, V. y Araneda, E.

2004 Principios orientadores y metodología para el estudio del Qhapaqñan en Atacama: Desde el Portezuelo del Inka hasta Río Grande. Chungara 36 (2): 463-481.

Conti, V.

2006. La ruta de los arrieros y el salitre. En Las Rutas del Capricornio Andino. Huellas milenarias de Antofagasta, San Pedro de Atacama, Jujuy y Salta, editado por Á. Cabeza, M. I. Hernández, L. Núñez y M. Vásquez, pp. 95-104. Consejo de Monumentos Nacionales, Santiago.

D'Orbigny, A.

1958 [1802-1857] Viaje a la América Meridional: Brasil, República del Uruguay, República Argentina, La Patagonia, República de Chile, República de Bolivia, República del Perú, Editorial Futuro, Buenos Aires.

González, J.

2008 La conquista de una frontera. Mentalidades y tecnologías en las vías de comunicación en el desierto 
de Atacama. Revista de Geografía Norte Grande 40: 23-46.

Haber, A.

2000 La mula y la imaginación en la arqueología de la puna de Atacama: una mirada indiscreta al paisaje. TAPA 19: 7-34.

Hidalgo, J.

1982 Fases de la rebelión indígena de 1781 en el corregimiento de Atacama y esquema de la inestabilidad política que la precede, 1749-1781. Anexo: 2 documentos inéditos contemporáneos. Chungara 9: 192-246.

Hidalgo, J.

1983 Dos documentos inéditos y un mapa de Cobija: informes del comisionado Dr. José Agustín de Arze, 1786-1787. Chungara 10: 138-145.

Hyslop, J.

1992 Qhapaqñan. El Sistema Vial Incaico, Instituto Andino de Estudios Arqueológicos, Lima.

Ingold, $\mathrm{T}$.

2000 The Perception of Environment. Essays on Livelihood, Dwelling and Skill. Routledge, Londres \& Nueva York.

Larraín, $\mathrm{H}$.

1977 Cobija y el interior de Antofagasta en 1864, relato de un viaje. Actas del VII Congreso Nacional de Arqueología Chilena, pp. 429-441, Altos de Vilches.

Lofstrom, W.

1974 Cobija, Bolivia's First Outlet to the Sea. The Americas 31: 185-205.

Lozano de Machuca, P.

1885 [1581] Carta del Factor de Potosí Juan Lozano de Machuca al virrey del Perú, en donde describe la provincia de los Lipes. En Relaciones Geográficas de Indias, editado por M. Jiménez de la Espada, Tomo II, Apéndice III, pp. xxixxviii. Ediciones Atlas, Madrid.

Nielsen, A.

2001 Ethnoarchaeological Perspectives on Caravan Trade in the South-Central Andes. En Ethnoarchaeology of Andean South America. Contributions to Andean Method and Theory, editado por L. Kuznar. pp. 163.201. International Monographs in Prehistory, Ann Arbor.

Pallière, L.

1945 [1858] Diario de Viaje por la América del Sud, con una introducción sobre la vida y obra del artista, ilustrada con acuarelas, grabados y dibujos desconocidos, ejecutados en América y Europa, Ediciones Peuser, Buenos Aires.

Philippi, R.

1860 Viage al Desierto de Atacama hecho de Orden del Gobierno de Chile en el Verano 1853-54, Librería Eduardo Anton, Halle, Sajonia.

Pimentel, G.

2003 Identidades, caravaneros y geoglifos en el Norte Grande de Chile: una aproximación teórico-metodológica. Boletín de la Sociedad Chilena de Arqueología 35/36: 67-80.
Pino Manríquez, J.

1836 [1786-1787] Descripción de la Villa de Potosi i de los partidos sujetos a su intendencia, Imprenta del Estado, Buenos Aires.

Pissis, A.

2011 [1812-1889] Geografía Física de la República de Chile, Producciones Gráficas Ltda., Santiago.

Platt, T.

1995 Ethnic Calendars and Market Interventions among the Ayllus of Lipes during the Nineteenth Century. En Ethnicity, Markets, and Migration in the Andes, editado por B. Larson y O. Harris, pp. 259-296. Duke University Press, Durham y Londres.

Platt, T.

1996 Producción, teconología y trabajo en la rivera de Potosí durante la república temprana. Ahila, cuadernos de historia latinoamericana, 3 (XXI): 1-59.

Pomar, L.

1887 Exploración hidrográfica entre la rada de Antofagasta i la desembocadura del Río Loa, por el Capitán de Fragata Don Luis Pomar, comandante de la cañonera Pilcomayo. En Anuario Hidrográfico de la Marina de Chile, 12. Imprenta Nacional, Santiago.

Risopatrón, L.

1910 La línea de frontera con la República de Bolivia. Sociedad Imprenta y Litografía Universo, Santiago.

Risopatrón, L.

1924 Diccionario Geográfico de Chile, Imprenta Universitaria, Santiago, Chile.

Sanhueza, C.

1991 Orígenes y desarrollo de la Arriería Indígena Colonial en Atacama. Siglos XVI-XVIII. Tesis para optar al grado de licenciado en historia, Pontificia Universidad Católica de Chile, Santiago.

Soja, E.

1985 The Spatiality of Social Life: Towards a Transformative Retheorization. En Social Relations and Spatial Structures, editado por D. Gregory y J. Urry, pp. 90-127. MacMillan, Londres.

Thomson, I.

2006 Los ferrocarriles del Capricornio Andino. En Las Rutas del Capricornio Andino. Huellas milenarias de Antofagasta, San Pedro de Atacama, Jujuy y Salta., editado por Á. Cabeza, M. I. Hernández, L. Núñez y M. Vásquez, pp. 139-149. Consejo de Monumentos Nacionales, Santiago.

Vásquez de Espinoza, A.

[1630]1948 Compendio y Descripción de las Indias Occidentales. Smithsonian Institution, Washington.

Vidal Gormaz, F.

1879 Noticias del desierto i sus recursos, Imprenta Nacional, Santiago.

\section{Notas}

1 Para simplificar la transformación de leguas a kilómetros, se emplea en adelante la equivalencia propuesta por Hyslop (1992: 173), según esta, una legua corresponde a cinco km.

2 De acuerdo con los datos obtenidos del cruce de itinerarios históricos, mediciones de imágenes satelitales y los resultados del modelo de movilidad realizado mediante herramientas SIG en función de la topografía del área de estudio, las jornadas de viaje con arreos de mulas o carretas entre Cobija y Calama habrían tenido una duración de 9 a 12 horas, cubriendo distancias de 40 a 57 km. Para más detalles véase Borie 2013 Ms.

3 En su recorrido de $17,5 \mathrm{~km}$, la cuesta de Guasilla asciende de $165 \mathrm{msm}$ a una cota de $1.113 \mathrm{msm}$ con una pendiente promedio de $13,4 \%$, mientras que la cuesta de Gatico, vía de 11,3 km de extensión, asciende de 51 a $1.321 \mathrm{msm}$ con una pendiente promedio de $11,5 \%$. 
